\title{
Insulation State On-Line Monitoring and Running Management of Large Generator
}

\author{
Qiudong Sun, Zhengxin Zhou, Weiqin Guo \\ School of electronic and electrical Engineering, Shanghai Second Polytechnic University, Shanghai, China \\ E-mail: qdsun@ee.sspu.cn, \{zxzhou,wqguo\}@sspu.cn \\ Received March 23, 2010; revised May 18, 2010; accepted July 4, 2010
}

\begin{abstract}
This study presented an insulation state monitoring method for large generator based on radio frequency (RF) technique. As an on-line condition monitor and the precondition of condition-based maintenance (CBM), the RF monitor used the high frequency current mutual inductor to detect the partial discharge signal from neutral wire of stator windings. According to the magnitude of indicative value of RF monitor, a five phase model was also proposed to manage the generator's running better. The practices show that the proposed method is effective.
\end{abstract}

Keywords: Large Generator, Partial Discharge, Radio Frequency Technique, On-Line Monitoring, Running Management

\section{Introduction}

Today, more and more power utilities are switching to money-saving and effective condition-based maintenance (CBM) programs for scheduling of machine maintenance and testing. Such a system can overcome the disadvantage of excess maintenance brought by the preventive maintenance [1]. It will determine the equipment's health, and act only when maintenance is actually necessary. Development in recent years have allowed extensive instrumen- tation of equipment such as condition monitoring to observing the state of the system, and together with better diagnosis tools for analyzing condition data, the main- tenance personnel of today are more than ever able to decide what is the right time to perform maintenance on some piece of equipment. Ideally CBM will allow the maintenance personnel to do only the right things, minimizing spare parts cost, system downtime and time spent on maintenance.

A large generator is a complicated machine system. Its breakdown is paroxysmal. If the accident once happens, the imperilment will be great, and the maintenance cost will also be great. A majority reason of its breakdown is the short circuit caused by its insulation being destroyed $[1,2]$. Due to the manufacturing and long time running of generator, the partial discharge (PD) of its stators is unavoidable [1]. This state can lead to aging of its main insulation, and eventually lead it to breakdown. There- fore, it is necessary for generator to be equipped an online condition monitoring system to observe its insulation state. Meanwhile, the on-line condition monitoring is the precondition of CBM. For a good CBM, it is far from enough if there is only an on-line condition monitoring system without being supported by a partial discharge analyzing technique. So, it is also necessary to study the relationship between the value of partial discharge and the insulation state of generator.

At present, the main methods for measuring the stator's partial discharge of large generator are the neutralpoint coupling detecting, coupling capacitor detecting, radio frequency detecting, detecting by partial discharge analyzer (PDA) and detecting by stator slot coupler (SSC) [3-6]. Generally, the partial discharge detecting systems are classified into two types by their frequency bandwidths. One works in narrow bandwidth, and the other in wide bandwidth, such as SSC. Generally, the former has a stronger anti-jamming capability and is sensitive for serious partial discharge, but it can not distinguish the discharge signal occurred inside or outside of generator $[2,3,5]$. Although the latter can collect plenty signals of partial discharge for analyzing, it is unacceptable because it needs imbedding a coupling sensor under the stator slot wedge and changing the insulation structure of stator windings $[2,3]$.

In this study, we propose an insulation state monitoring method for generators based on radio frequency monitoring technique. We choose the narrow bandwidth 
technique to design the partial discharge detecting system, which can monitor the insulation state of generator. We also give some advices for generator's running management according to the RF signal level produced by partial discharge and CBM experience.

This study is organized as follows. In Section 2, we give the radio frequency monitoring technique about the partial discharge, insulation deterioration and RF measurement method. We also give the frame of RF Monitor and the on-line monitoring architecture in this section. Section 3 presents an on-line evaluation method of insulation state. Section 4 gave some application examples, and shows that the proposed scheme yields more effective through practices. Section 5 gives the conclusion of this study.

\section{Radio Frequency Monitoring}

\subsection{Partial Discharge}

Partial discharge can be described as an electrical pulse or discharge in a gas-filled void or on a dielectric surface of a solid or liquid insulation system. This pulse or discharge only partially bridges the gap between phase insulation to ground, or phase-to-phase insulation. A full discharge would be a complete fault between line potential and ground [2].

These discharges might occur in any void between the copper conductor and ground. The voids may be located between the copper conductor and insulation wall, or internal to the insulation itself, or between the outer insulation wall and the grounded frame [2].

These discharges also might occur at the terminal of winding. Its surface contamination and moisture creates the surface discharge and lightning.

\subsection{Insulation Deterioration and Complete Failure}

Insulation degradation is frequently linked to partial discharges. The partial discharges are effectively small sparks occurring within the insulation system, therefore deteriorating the insulation, and can eventually result in complete insulation failure [2].

At many times, the winding insulation deterioration can be represented by the developing and forming process of its strand breaking. Those wires of windings, which are located at the upper winding-bar with the same slot and the same phase endured maximal magnetic force, upmost temperature and supreme electric strength, and the wires near by slot wedge, especially the wires located at seamed edge, are easily deteriorated. The deterioration process of stator windings can be described as Figure 1. In this figure, those phenomena labeled by symbol "*” can be detected by RF monitor or superheater.

\subsection{Partial Discharge Measurement Method}

Partial discharges are high frequency pulses originating at various sections within an insulation system [1,2]. These pulses generate a voltage and current signal into the insulation, returning through a ground path. The partial discharge measurement can be implemented by radio frequency monitoring techniques (RFMT).

We use the HF current transducer (CT), which is nipped tightly at the proper unshielded position of neutral wire of stator winding, to detect the RF current. The RF measurement connection and technique are as shown in Figure 2. In this figure, the RF monitor is a high sensitive measurement meter with a magnitude of $\mu \mathrm{V}$ quasi- peek value.

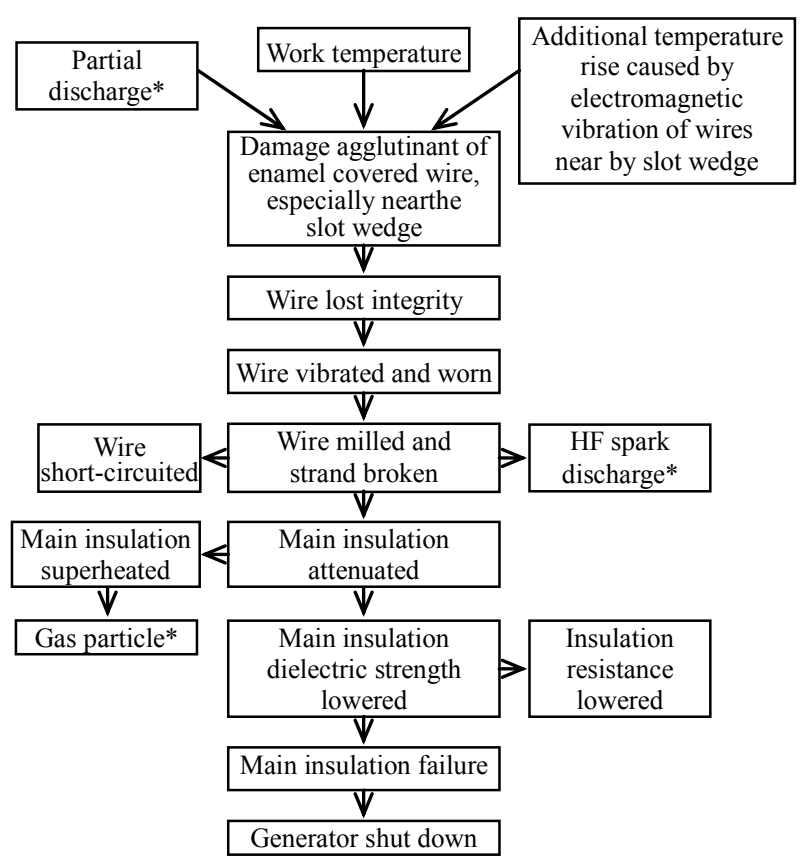

Figure 1. Deterioration process of stator windings.

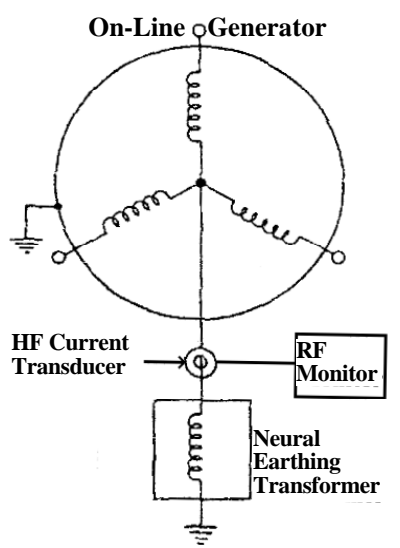

Figure 2. The measurement connection method. 


\subsection{RF Monitor}

As mentioned above, the RFMT can be classified into two types: narrow bandwidth and wide bandwidth. The narrow bandwidth technique is applied in our monitoring system because it has strong anti-jamming capability.

Our RF monitor (or Insulation Monitor) is composed of receiver (includes crystal filter, RF logarithm amplifyier, quasi-peek value detector), logical judging processor and output alarming circuit as shown in Figure 3. Its centre frequency is $1 \mathrm{MHz},-3 \mathrm{~dB}$ bandwidth is $5 \mathrm{kHz}$, $-60 \mathrm{~dB}$ bandwidth is $20 \mathrm{kHz}$, the dynamic input range is $10 \mu \mathrm{V} \sim 10000 \mu \mathrm{V}$, input resistance is $50 \Omega$. It also has a greater than $60 \mathrm{~dB}$ suppressing circuit to attenuate the false signals and to improve its capacity to defense abrupt disturbing.

\subsection{On-Line Monitoring Architecture}

The on-line monitoring system is composed of RF monitor, HF current transducer (CT) and telecontrol board mainly as shown in Figure 4. As a probe, the HF current transducer is used to detect the RF current. The RF Monitor is used for on-line monitoring the state of interior faults of generator and unwonted alarming. The telecontrol board equipment is placed far from the generator to remote monitoring its insulation state. It has the same control functions, indication buttons and the voice and light alarming set with the main monitor. It also has a graph recorder for plotting and saving the output signal from RF Monitor. Finally, the telecontrol board is connected by USB interface into a distributed control system (DCS), which can store the RF signal timely, process and analyze the RF signal, and be accessed remotely by the users (diagnosis personnel ) far from internet.

\section{On-Line Evaluation of Insulation State}

\subsection{Running Experience}

According to the experience from more than 360 set RF monitoring practices, we have obtained the following knowledge:

When the RF signal level is less than $300 \mu \mathrm{V}$ or fluctuating about this level and it is independent of generator's load, there is only a small discharge in the generator system. The fact shows that the insulation state of generator system is good or regular.

The RF signal level of greater than $1000 \mu \mathrm{V}$ indicates that there is a bigger discharge in the generator system. Here, we should compare this moment data with that of forepassed and consider the factors as follows to evaluate the insulation state:

1) The relationship between RF signal level and generator's load.

2) The amplitude of RF signal is relative invariable or changing randomly.

3) The RF signal rises tardily or abruptly.

4) We should also integrate the RF signal with the traditional testing and the work condition change testing to judge the insulation fault happened inside or outside the generator.

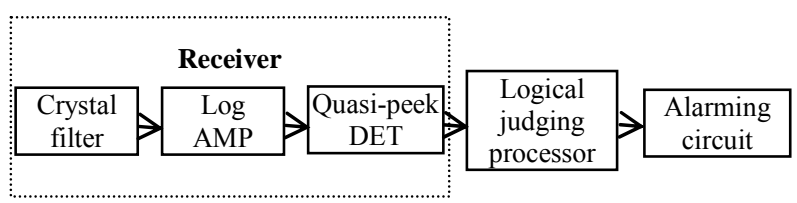

Figure 3. Frame of insulation monitor.

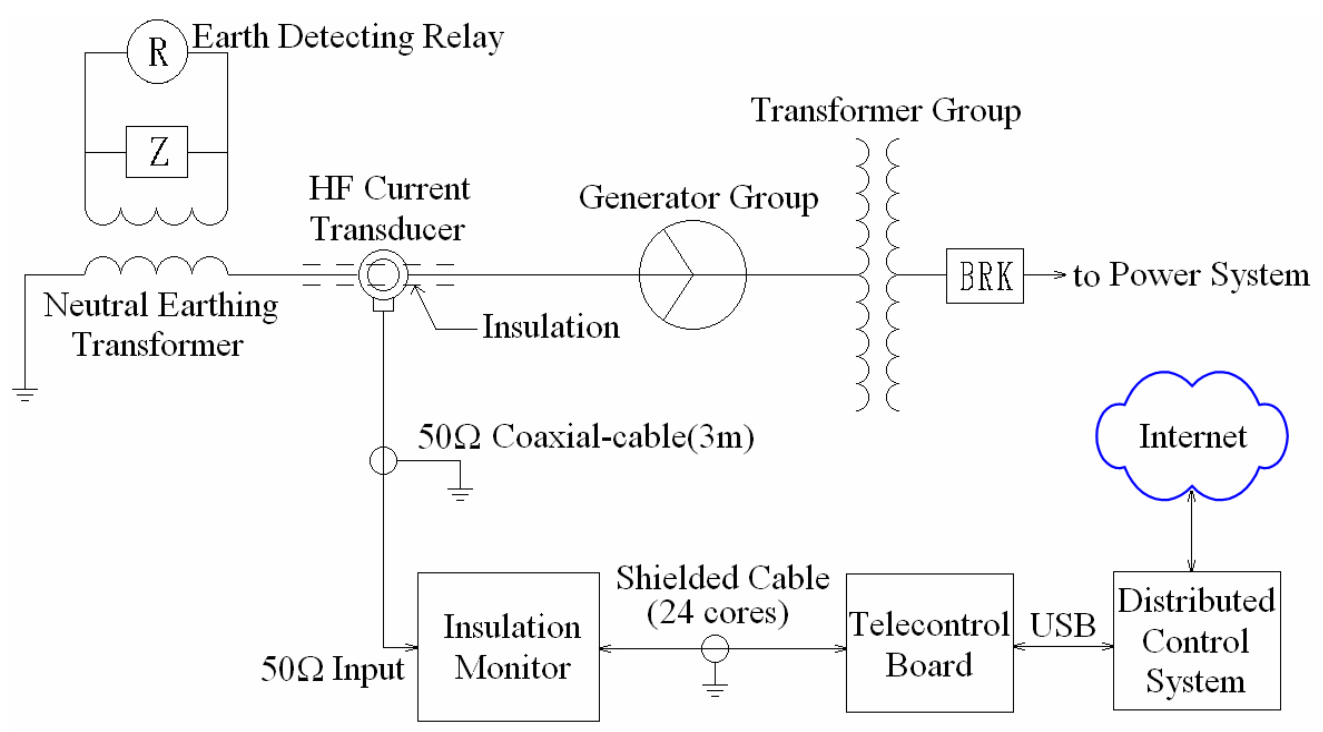

Figure 4. The on-line monitoring architecture of RF Monitor. 
We have to admit that the generator need not always shut down when the RF signal rises to a set level, and $1000 \mu \mathrm{V}$ RF signal is not an absolute threshold to judge the discharge happened inside the stator of generator.

In the condition-based maintenance system, it is impossible to judge what kind fault of generator happened or whether the generator need shut down or not, just by one apparatus or one signal. Therefore, we need other testing equipment and some experienced field experts to support the condition-based maintenance for generator.

\subsection{Relationship between Insulation State and RF Signal}

According to the running experience and analysis in Subsection 3.1, we propose a five advice model for generator's running management corresponding to the five pha- ses of insulation state as shown in Figure 5. This model is also a result of practice statistics. It is an eligible mo- del for most circumstances.

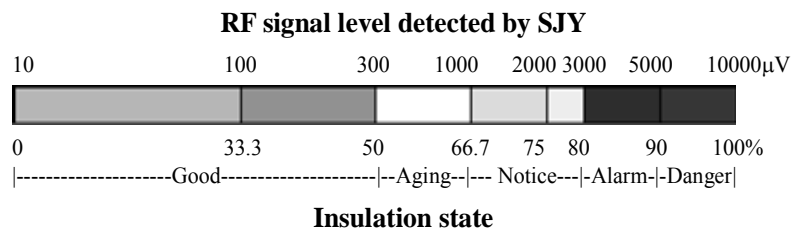

Figure 5. Relationship between insulation state and RF signal.

\subsection{Five Advice Model for Running Manage- ment}

In Figure 5, each phase has a corresponding advice for generator's running management as shown in Table 1.

\section{Applications}

Up to now, more than 360 sets of our RF monitor (SJY) have been launched into various power generating sets, which include thermal power generators, water power generators, nuclear power generators and gas turbine generators. Their equipped capacitors are from $100 \mathrm{MW}$ to $1000 \mathrm{MW}$.

Our RF monitors have predicted various insulation failures successfully in practices. For example, a 300 MW hydrogen-cooled generator of a Power Plant has been run 7 years. Some day the equipped RF monitor output an abnormal signal as shown in Figure 6 and alarmed. The magnitude of abnormal signal was about hundreds of $\mu \mathrm{V}$. By analyzing the RF signal, we judged that the terminal of stator winding has damaged to result in the partial discharge like this. And we also gave an advice to user to reconstruct the stator winding. After its stator winding reconstructed, the generator got back in order. And the RF monitor went back to indicate a normal signal as shown in Figure 7. The magnitude of RF signal had dropped to a normal level of tens of $\mu \mathrm{V}$.

Table 1. Insulation states of generator evaluated by RF signal and its running management advices.

\begin{tabular}{|c|c|c|}
\hline Insulation state & RF signal level $(\mu \mathrm{V})$ & Running management of generator from field experts \\
\hline Good & $\leq 300$ & The generator is allowed long-term running. \\
\hline Aging & $300 \sim 1000$ & $\begin{array}{l}\text { The insulation state of generator is in the interim from good to bad. It is allowed running unceasingly. } \\
\text { But we should notice to observe the trend of insulation degradation. }\end{array}$ \\
\hline Notice & $1000 \sim 3000$ & We should notice to observe the running state of generator or arrange the maintenance scheme. \\
\hline Alarm & $3000 \sim 5000$ & $\begin{array}{l}\text { We should pay attention to the trend of the running state change and the work condition change } \\
\text { testing. The generator is needed to shut down at appropriate time. }\end{array}$ \\
\hline Danger & $\geq 5000$ & $\begin{array}{l}\text { We should integrate the indicative value of RF signal with other symptoms to judge whether the } \\
\text { generator is necessary to shut down or not. }\end{array}$ \\
\hline
\end{tabular}

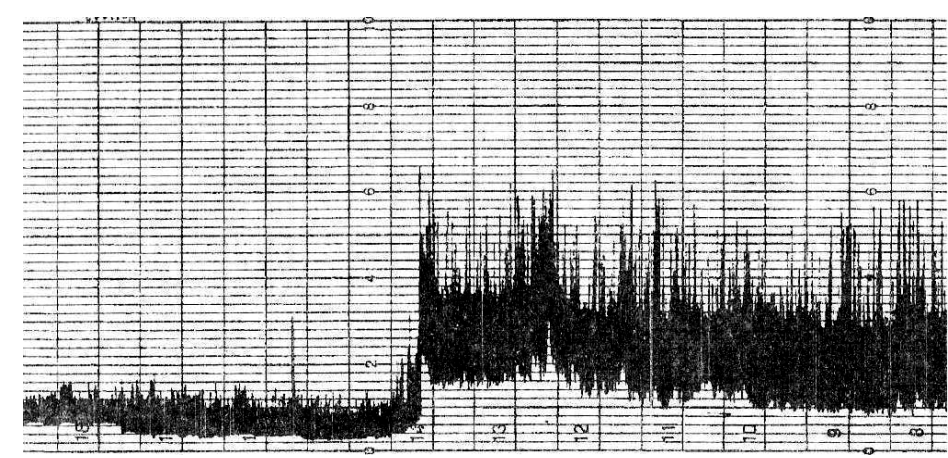

Figure 6. An abnormal signal of RF Monitor. 


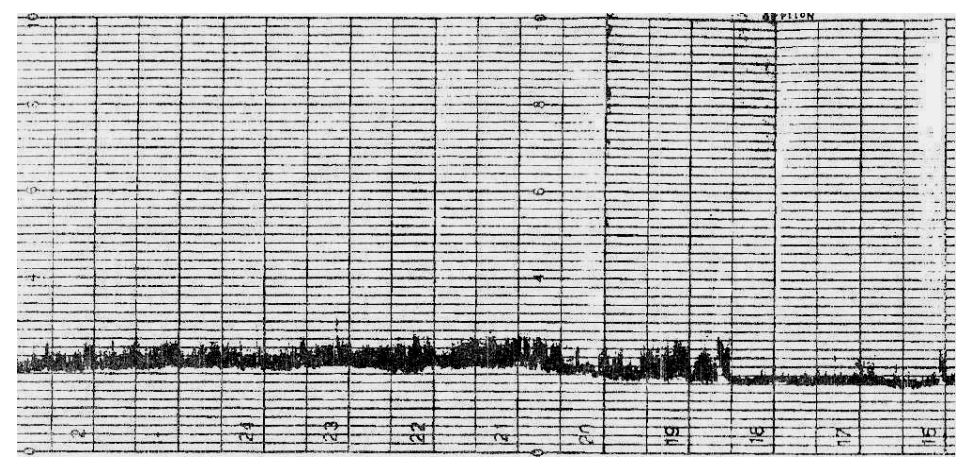

Figure 7. A normal signal of RF Monitor.

As mentioned in Section 1, it is necessary to install a $\mathrm{RF}$ monitor into the complicated generator set for online monitoring its insulation state. If the RF monitor has been installed, but we can not unscramble its signal, then the RF monitor like this is just an ornament and it is useless. We should better to integrate the RF signal with other diagnosing system to monitor the generator's insulation state and give a diagnosis conclusion and a running management advice.

Also we should indicate that the RF monitor is not enough apparatus or RF signal is not enough symptoms to judge what kind fault of generator happened or whether the generator need shut down or not. Therefore, we need some other testing equipment and some experienced field experts to support the condition-based maintenance for generator.

\section{Conclusions}

This study presented an insulation state monitoring approach for CBM of generators. In our approach, the RF monitor with strong anti-jamming capability and the online monitoring system were designed to detect the partial discharge signal caused by the insulation degradation of generators. In order to run generator better, we proposed a five phase running management model according to the magnitude of indicative value of RF monitor (SJY). The practices demonstrated that the proposed method is effective.

\section{Acknowledgements}

This research project was supported by the Key Disciplines of Shanghai Municipal Education Commission under Grant No. J51801.

\section{References}

[1] W. Q. Guo, "On-Line Insulation Monitoring and Condition Maintenance to Generators," Journal of Shanghai Second Polytechnic University, No. 1, 2002, pp.

[2] 20-36oletti and A. Golubev, "Partial Discharge Theory and Technologies Related to Traditional Testing Methods of Large Rotating Apparatus," 34th IAS Annual Meeting, Phoenix, Vol. 2, October 1999, pp. 967-981.

[3] C. J. Huang, W. Y. Yu, P. Gabe and W. Wei, "Partial Discharge On-Line Monitoring and its Application to the Large Generators," Large Electric Machine and Hydraulic Turbine, No. 6, 2000, pp. 33-38.

[4] X. L. Chen, X. P. Cao, Y. H. Lu, B. Yue, Y. H. Cheng, and H. K. Xie, "Field Detection of Ultra-Wide Band Partial Discharge for Generator Stator Insulation," Electric Power, Vol. 35, No. 3, 2002, pp. 31-34.

[5] G. Stone, V. Warren and M. Fenger, "Diagnostic Information Obtained from Examining a Large Stator Winding PD Result Database," Proceedings of the International Symposium on Electrical Insulating Materials, Vol. 33, 2001, pp. 635-640.

[6] G. Stone, "Advancements during the Past Quarter Century in On-Line Monitoring of Motor and Generator Winding Insulation," IEEE Transactions on Dielectrics and Electrical Insulation, Vol. 9, No. 5, 2002, pp. 746751. 